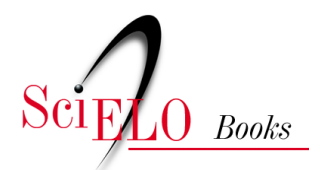

ed

\title{
Apresentação - O Programa Minha Casa Minha Vida: habitação e produção do espaço urbano em diferentes escalas e perspectivas
}

\author{
Doralice Sátyro Maia \\ Glaucio José Marafon
}

\section{SciELO Books / SciELO Livros / SciELO Libros}

MAIA, D. S., and MARAFON, G. J. Apresentação - O Programa Minha Casa Minha Vida: habitação e produção do espaço urbano em diferentes escalas e perspectivas. In.: MAIA, D. S., and MARAFON, G. J., eds. O programa Minha Casa Minha Vida: habitação e produção do espaço urbano em diferentes escalas e perspectivas [online]. Rio de Janeiro: EDUERJ, 2020, pp. 7-18. ISBN: 978-65-00-03029-7. https://doi.org/10.7476/9786500030297.0001.

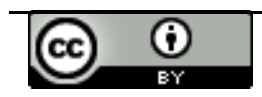

All the contents of this work, except where otherwise noted, is licensed under a Creative Commons Attribution 4.0 International license.

Todo o conteúdo deste trabalho, exceto quando houver ressalva, é publicado sob a licença Creative Commons Atribição 4.0.

Todo el contenido de esta obra, excepto donde se indique lo contrario, está bajo licencia de la licencia Creative Commons Reconocimento 4.0. 


\section{Apresentação - O Programa Minha Casa Minha Vida: habitação e produção do espaço urbano em diferentes escalas e perspectivas}

Doralice Sátyro Maia Glaucio José Marafon

A escrita de um texto em conjunto requer, antes de tudo, uma decisão dos autores de como se dará a sua estrutura e o que compete a cada um registrar. Optamos por iniciar esta coletânea com algumas anotaçóes sobre a pesquisa que a originou, como também sobre o tema que se faz presente nos capítulos da obra, além de uma rápida apresentação sobre eles.

\section{Notas de Pesquisa}

Este livro é resultado da pesquisa "Grandes infraestruturas urbanas, ensino superior e desenvolvimento regional: reconfigurando as relaçóes entre as cidades médias, as cidades pequenas e o campo", realizada com recursos da Coordenação de Aperfeiçoamento de Pessoal do Ensino Superior (Capes) e do Ministério da Integração entre 2013 e 2018. A pesquisa foi desenvolvida em três instituiçôes: Universidade Estadual Paulista - UNESP (campus Presidente Prudente-SP), Universidade do Estado do Rio de Janeiro - UERJ (campus Maracanã-RJ) e Universidade Federal da Paraíba - UFPB (campus João Pessoa-PB). Trata-se, pois de um trabalho realizado por três equipes de pesquisadores e professores dos cursos de Geografia e dos Programas de Pós-Graduação em Geografia das respectivas instituiçôes.

A pesquisa teve seis objetivos amplos: 
1. Fortalecer as relaçóes entre equipes de pesquisa que são associadas à Rede de Pesquisadores sobre Cidades Médias, ampliando suas frentes de trabalho científico e contribuindo para a formação de recursos humanos em nível de pós-graduação;

2. Aprofundar as relaçóes acadêmicas entre os programas de pósgraduação integrados a esta proposta, de modo que, de um lado, o mais consolidado contribua para o fortalecimento dos outros dois e, de outro, a interação entre os três favoreça a troca de ideias e de formas de se organizar a pós-graduação e se fazer pesquisa;

3. Realizar estudo nas cidades de Campina Grande e Patos, na Paraíba; Caruaru, em Pernambuco; Campos, no norte fluminense; Marília e Presidente Prudente, no oeste paulista - o que se desdobra em dois objetivos específicos:

a. 3.1. conhecer melhor a realidade dessas cidades, suas relaçóes com o campo e as regióes que comandam;

b. 3.2. oferecer elementos para algum nível de generalização em pesquisas semelhantes por meio de desenvolvimento de metodologia de investigação científica.

4. Ampliar o conhecimento científico sobre o tema, contribuindo para o desenvolvimento regional nos territórios estudados e para a diminuição de disparidades regionais no país por meio de estudos comparativos, que náo têm como télos a ideia de que as regióes devem ser homogêneas; mas sim que deve haver, por parte das políticas públicas, compromisso com a equidade de condiçôes para toda a sociedade, o que implica em dotação territorial dos meios necessários para tal;

5. Analisar as repercussóes do Programa Minha Casa Minha Vida nas cidades de Campina Grande e Patos, na Paraíba; Caruaru, em Pernambuco; Campos, no norte fluminense; Marília e Presidente Prudente, no Estado de São Paulo, no que se refere à produção/ expansão/consumo da cidade, à dinâmica econômica e regional e às novas relaçóes entre a cidade e o campo;

6. Investigar as implicaçóes socioespaciais resultantes da implantação de novos cursos e de novos campi em algumas cidades localizadas no interior do Estado da Paraíba, particularmente em Campina Grande e nos municípios da área de sua influência; em Caruaru, 
no estado de Pernambuco; em Campos, no norte fluminense; e em Marília e Presidente Prudente, procurando avaliar como estas instituiçóes atendem moradores do campo e de cidades pequenas.

Observe-se que os dois primeiros objetivos procuraram atender aos propósitos maiores da Capes - fomentar a "expansão e consolidação da pós-graduaçáo Stricto Sensu (mestrado e doutorado) em todos os estados da Federação." Dentre os resultados, destacam-se o fortalecimento das relaçóes entre as equipes e seus respectivos programas de pós-graduaçáo por meio de missóes docência, participação de docentes em bancas examinadoras, formação de graduandos, mestrandos e doutorandos, inclusive com a realização de doutorado-sanduíche em instituição estrangeira, além das apresentaçóes de trabalhos em eventos científicos nacionais e internacionais e das publicaçóes em anais de eventos, periódicos e livros.

No que se refere aos objetivos 3, 4, 5 e 6, o foco é a concretização da pesquisa em dois principais eixos de investigação: as repercussóes do Programa Minha Casa Minha Vida nas cidades eleitas pelas três equipes e as implicaçóes socioespaciais derivadas da política de implantação de novos cursos e de novos campi de ensino superior. A concretizaçáo desses objetivos resultou em algumas publicaçóes já realizadas e serão apresentadas de forma mais ampliada nos dois livros organizados pelos coordenadores da pesquisa. O primeiro volume, aqui apresentado, dedica-se ao Programa Minha Casa Minha Vida, já o segundo tratará das repercussóes da política de ampliação do ensino superior e da relação entre cidade e campo.

Muito embora esta publicação tenha como propósito principal apresentar e divulgar os resultados da pesquisa, decidiu-se ampliar a discussão convidando alguns autores que trabalharam com a temática em outras realidades ou que a estudaram com outros recursos, mas que se somam aos estudos realizados por nós.

Desta forma, o leitor não vai encontrar somente textos que trazem análises e resultados de pesquisas concretizadas com recursos do Edital Pró-Integração Capes/MIntegração, mas também estudos feitos no âmbito de outros programas de pós-graduação e que aqui se somam. No mesmo sentido, apesar de se ter as cidades médias como principal recorte espacial, entende-se

1 Disponível em https://www.capes.gov.br/historia-e-missao. Acesso em 18 out. 2019. 
que o debate a respeito do Programa Minha Casa Minha Vida e da política de ampliação do ensino superior náo deve se restringir às realidades urbanas classificadas como médias ou pequenas, pois tais políticas se deram fortemente também nas realidades metropolitanas. Assim sendo, além dos estudos concretizados nas cidades indicadas no projeto inicial - Campina Grande e Patos na Paraíba, Caruaru em Pernambuco, e Campos dos Goytacazes no Rio de Janeiro -, amplia-se o leque de cidades estudadas, algumas pelo grupo de pesquisadores - a exemplo de Resende, no Rio de Janeiro -, e outras que se somaram uma vez que os autores sáo pesquisadores que integram os grupos de pesquisa liderados pelos coordenadores do projeto. Assim, este volume reúne textos que tratam do Programa Minha Casa Minha Vida em realidades metropolitanas como Recife e Rio de Janeiro, em capitais como João Pessoa, ou em cidades pequenas localizadas em outras unidades federativas, como Russas, no Ceará. Acrescenta-se que os autores dos capítulos desta obra são pesquisadores que mantêm diálogos e são parceiros dos coordenadores da pesquisa em outros projetos e outras atividades. Além disso, a decisão por se ampliar o conjunto de autores e de realidades analisadas deu-se com o propósito de consolidar novas parcerias de pesquisa e de redes de intercâmbio entre os grupos de pesquisa e também entre os programas de pós-graduaçáo.

Explicita-se ainda que, embora o projeto tenha indicado uma matriz metodológica para a pesquisa, as equipes e os autores tiveram liberdade de eleger os aportes teórico-metodológicos. Tal decisão possibilitou a diversidade das leituras e das reflexóes sobre as realidades estudadas. Os organizadores entendem que, apesar de exigir o rigor acadêmico-científico, o fazer do conhecimento científico também clama pela diversidade teórica e pela liberdade de escolha e de ideias. Desta forma, destaca-se que os autores dos capítulos são responsáveis pelas suas posturas teórico-metodológicas e pelas suas conclusóes. Contudo, isso não significa que os organizadores se eximem da responsabilidade do que se publica, pois os textos apresentados foram lidos e aprovados pelo que se considera uma postura acadêmico-científica. Evidentemente há textos que revelam maior aprofundamento teórico, outros trazem mais resultados da pesquisa empírica, uns são mais descritivos, outros mais analíticos, enfim, um "retrato" da diversidade acadêmica dos que se debruçaram e que continuam a mergulhar nesse grande universo do que se constituiu as cidades produzidas pela política nacional de habitação do Programa Minha Casa Minha Vida. 
Vale registrar que escrevemos a apresentação de um livro sobre uma política pública tão importante no momento que se anuncia o seu término sem uma substituição; ou seja, finalizamos a obra sem termos clareza do que será desenvolvido enquanto política dirigida à habitação, tampouco à habitação de interesse social.

\section{O Programa Minha Casa Minha Vida (PMCMV)}

Em quase todos os capítulos, o leitor vai encontrar algumas notas a respeito do PMCMV. Contudo, faremos aqui uma síntese do programa no seu transcurso. Ainda que muitos autores já tenham escrito a respeito, cabe aqui apresentá-lo, afinal é sobre ele que trata este volume. ${ }^{2}$

O Programa Minha Casa Minha Vida foi criado pelo Governo Federal por meio da lei $n^{\circ} 11.977 / 2009$ e constitui-se em uma política voltada para a habitação. No decurso de 2009 a 2019 o programa apresenta três versóes, denominadas de fases. Desde a sua concepção inicial, destinava-se a diferentes faixas de renda, tendo como o máximo dez salários mínimos. ${ }^{3}$ Portanto, apresentava na sua concepção três faixas de financiamento, e a participação do Estado variava conforme as faixas de renda das famílias. A fase 1 é implementada de 2009 a 2011; a fase 2, de 2011 a 2014 e a fase 3, de 2016 a 2019. Na primeira fase, as faixas de renda foram estabelecidas de acordo com o número de salários mínimos e, a partir da segunda fase, os valores foram fixados. $\mathrm{Na}$ fase 2 , as faixas da população se apresentaram da seguinte forma:

- Faixa 1 - famílias com renda de até $\mathrm{R} \$ 1.600$ reais;

- Faixa 2 - famílias com renda de até $\mathrm{R} \$ 3.275$ reais;

- Faixa 3 - famílias com renda entre $\mathrm{R} \$ 3.275$ até $\mathrm{R} \$ 5$ mil reais.

Em 2016, na fase 3 do programa, houve um pequeno ajuste nos valores, acrescentando mais uma faixa de renda, denominada de Faixa 1,5. Nessa fase, as faixas estabelecidas foram:

2 Dentre as várias obras, trabalhos de conclusão de doutorado, mestrado e graduação, além de artigos em periódicos, cita-se o livro organizado por Adauto Cardoso (2013).

3 Alterado em 2015 pela lei $\mathrm{n}^{\circ} 13.173$. 
- Faixa 1 - famílias com renda de até $\mathrm{R} \$ 1.800$ reais;

- Faixa 1,5 - famílias com renda de até R $\$ 2.600$ reais;

- Faixa 2 - famílias com renda de até $\mathrm{R} \$ 4.000$ reais;

- Faixa 3 - famílias com renda de até R $\$ 7.000$ reais.

Deve-se considerar o propósito do PMCMV, definido na lei 11.977 de 2009:

Art. 1ํㅡ O Programa Minha Casa, Minha Vida - PMCMV tem por finalidade criar mecanismos de incentivo à produção e aquisição de novas unidades habitacionais ou requalificação de imóveis urbanos e produção ou reforma de habitações rurais, para famílias com renda mensal de até $\mathrm{R}$ \$ 4.650,00 (quatro mil, seiscentos e cinquenta reais) e compreende os seguintes subprogramas:

I - o Programa Nacional de Habitaçấo Urbana (PNHU)

II - o Programa Nacional de Habitação Rural (PNHR)

Para a implementação do referido programa, a lei determina que se observe a disponibilidade orçamentária e financeira e, dentre as participaçóes, estabelece a do "Fundo de Arrendamento Residencial (FAR), mediante integralização de cotas e transferirá recursos ao Fundo de Desenvolvimento Social (FDS)". ${ }^{4}$

Em conformidade com o perfil socioeconômico, definidas pelas faixas de renda, o PMCMV apresenta duas matrizes de financiamento para a habitação: um voltado para o que é chamado de Habitação de Interesse Social, e o outro destinado à Habitação de Mercado. Shimbo (2012) denomina de dois subsistemas: o primeiro corresponde à faixa 1, que na primeira versão do programa correspondia às famílias com renda até três salários mínimos, na fase 2 às famílias com renda até $\mathrm{R} \$ 1.600,00$ (mil e seiscentos reais) e na fase 3 às famílias com renda até $\mathrm{R} \$ 1.800,00$ (mil e oitocentos reais). Observe-se que no decurso de 2009 a 2019 houve uma variação nos valores do salário mínimo, tendo-se uma significativa alteração especialmente entre os anos de 2009 a 2016 (Tabela 1):

${ }^{4}$ Lei 11.977 de 2009. 
Tabela 1 - Valores do Salário Mínimo Brasileiro e Percentual de aumento por ano

\begin{tabular}{c|c|c|c}
\hline \multirow{2}{*}{ Ano } & Vigência & Valor (R\$) & $\begin{array}{c}\text { Percentual de } \\
\text { aumento }\end{array}$ \\
\hline 2009 & $01 / 01 / 2009$ & 465,00 & 12,05 \\
\hline 2010 & $01 / 01 / 2010$ & 510,00 & 9,68 \\
\hline 2011 & $01 / 03 / 2011$ & 545,00 & 5,88 \\
\hline 2012 & $01 / 01 / 2012$ & 622,00 & 14,13 \\
\hline 2013 & $01 / 01 / 2013$ & 678,00 & 9,00 \\
\hline 2014 & $01 / 01 / 2014$ & 724,00 & 6,78 \\
\hline 2015 & $01 / 01 / 2015$ & 788,00 & 8,84 \\
\hline 2016 & $01 / 01 / 2016$ & 880,00 & 11,68 \\
\hline 2017 & $01 / 01 / 2017$ & 937,00 & 6,48 \\
\hline 2018 & $01 / 01 / 2018$ & 954,00 & 1,81 \\
\hline 2019 & $01 / 01 / 2019$ & 998,00 & 4,61 \\
\hline
\end{tabular}

Fonte: https:/www.contabeis.com.br/tabelas/salario-minimo/ [Acesso em 18 out. 2019].

A tabela mostra os percentuais de aumento do salário mínimo por ano, o que explica a alteração na definição das faixas de renda do PMCMV da fase 1 para a fase 2. Pois, se inicialmente definia-se como Faixa 1 as famílias até 3 salários mínimos, em 2009 tal montante correspondia à renda máxima de $\mathrm{R} \$ 1.395,00$ (mil e trezentos e noventa e cinco reais), já em 2011, o valor era de $\mathrm{R} \$ 1.635,00$ (mil seiscentos e trinta e cinco reais). Assim, o texto da fase 2 , ao alterar a redação, define os valores por faixa correspondente ao salário mínimo do ano de 2011. Por conseguinte, ao se diminuir o ajuste do salário mínimo, reduz-se a renda máxima das famílias inseridas em cada faixa. Dessa forma, em 2016, a faixa 1 , ao ter como valor máximo de renda $\mathrm{R} \$ 1.800,00$ (mil e oitocentos reais), refere-se às famílias com renda até 2 salários mínimos e em 2019 a 1,8 salários mínimos.

Ao se analisar as modificaçóes feitas nas leis do PMCMV, outro ponto que merece destaque é a referência à regularização fundiária que, desde a sua primeira concepção (Lei no 11.977/2009) até 2017, apresentava um capítulo destinado à Regularização Fundiária de Assentamentos Urbanos. Este capítulo é revogado pela Lei $\mathrm{n}^{\circ} 13.465$ de 2017. A partir de então, uma das principais diretrizes do PMCMV, que estava direcionada à população de 
menor renda, portanto, à demanda habitacional de interesse social, é completamente eliminada.

A segunda matriz do programa, aquela destinada à habitação de mercado, tinha como propósito estimular a economia brasileira, considerando a crise econômica mundial eclodida nos Estados Unidos em 2008. Vários são os autores que discutiram essa questáo e ressaltaram muitas vezes o "desvio" de prioridades de um programa que deveria ser destinado a dirimir o problema habitacional brasileiro. A autora Lúcia Shimbo (2012) refere-se ao "Pacote Habitacional Minha Casa, Minha Vida" e explica:

Esse pacote formalizou o 'espírito' já corrente, desde meados dos anos 1990, de incentivo à provisão privada de habitação, por meio de medidas regulatórias e do aumento de recursos destinados ao financiamento habitacional empreendidas recentemente. Portanto, se levarmos em consideração esse contexto recente, o MCMV não pode ser encarado à revelia de uma política nacional de habitação. (Shimbo, 2012, p. 54).

A autora complementa: "o pacote foi apresentado como uma das principais açôes do governo em reação à crise econômica internacional e também como uma política social de grande escala”. (p. 54). Dessa forma, o programa ao mesmo tempo que atendia à falta de moradia, direciona-se para os interesses capitalistas, inclusive ao capital financeiro.

Dentre os autores que discutiram os problemas da política habitacional elaborada desde a concepçáo do PMCMV, estando voltada especialmente para o mercado imobiliário cita-se Rolnik e Nakano (2009), Cardoso e Aragáo (2011), Shimbo (2011) e Campos (2011). Torna-se evidente, que apesar do propósito em atender a uma demanda social, o "Programa não só foi criado para como também pelo setor imobiliário". (Lucena e Maia, 2016, p. 2, grifos das autoras). Além disso, há que se ressaltar as repercussóes no mercado imobiliário que incide diretamente na demanda habitacional, ou seja,

[...] o volume de recursos mobilizados, ao garantir um mercado consumidor sólido e seguro, ampliou a demanda por terra, elevando os preços imobiliários, provocando posteriormente o aumento do teto dos financiamentos, como foi anunciado em 2012 pelo Conselho Curador do FGTS, além de outras tantas consequências. (Lucena e Maia, 2016, p. 3). 
Muito embora os capítulos que compóem esta obra mostrem dados e discutam de forma mais aprofundada as repercussóes do referido programa na produção do espaço urbano, vale trazer alguns dados. Tem-se que, no período de 2009 a 2016, de acordo com os dados fornecidos pelo então Ministério das Cidades, foram contratadas um total de 4,2 milhôes de moradias. O montante é por demais representativo, revelando a produção de cidades para além do que se tinha de tecido urbano consolidado.

Para além das alteraçóes feitas na concepçáo do programa desde a sua primeira elaboraçáo, há que se registrar as mudanças que se referem ao projeto arquitetônico das habitaçôes que, após algumas iniciativas, inclusive a de financiamento de projetos de pesquisas voltados especificamente para analisarem o PMCMV, foram estabelecidas exigências como a inclusão da acessibilidade, do padrão construtivo e de materiais, dos equipamentos públicos (escolas, creches, unidades de saúde), da pavimentação do acesso aos conjuntos habitacionais e ainda do acréscimo de equipamentos, entre eles o sistema de aquecimento solar de água. Há, portanto, muito a ser analisado e discutido para se ter reflexões mais complexas a respeito das repercussóes do PMCMV na produçáo do espaço urbano.

Os textos que compóem os capítulos aqui apresentados traduzem algumas repercussóes do Programa Minha Casa Minha Vida na produção, expansão e consumo das cidades eleitas para a pesquisa - e em outras já assinaladas. Tais registros foram realizados utilizando-se diferentes recursos metodológicos e o nível de aprofundamento variou entre as equipes, entre os autores e seus respectivos trabalhos.

\section{Uma síntese da composiçáo do livro}

O livro encontra-se organizado em onze capítulos. No primeiro, de Flaviane Ramos Santos e Maria Encarnaçáo Sposito, "Teorias de localizaçáo: do espaço absoluto e relativo ao espaço relacional", é feita uma breve contextualização histórica das principais formulaçôes teóricas e dos modelos de localizaçáo das atividades urbanas. No segundo capítulo, de Luciana de Carvalho Gomes, "Metrópole em movimento: Reflexões sobre a produção do espaço na Região Metropolitana do Recife a partir da localização dos empreendimentos do PMCMV", se evidencia como a localizaçáo dos empreendimentos do PMCMV na RMR estão subordinados primeiramente aos 
interesses da produção empresarial da moradia que à real demanda do déficit habitacional ou a capacidade de oferta de infraestrutura dos municípios. Alimentam, assim, uma lógica segregacionista, na qual o agente privado determina onde vivem ricos e pobres. As localizaçóes periféricas (definidas pela produção empresarial) das moradias acabam por transformar, em primeiro plano, o espaço urbano municipal (formal ou informalmente) diante das necessidades de produção, reprodução e consumo dos moradores.

O terceiro artigo, de autoria de Angela Moulin Simóes Penalva Santos e Pedro Henrique Ramos Prado Vasques, "O Programa Minha Casa Minha Vida contribui para a construção do direito social à moradia? A experiência no Estado do Rio de Janeiro", analisa como a experiência do MCMV no Estado do Rio de Janeiro ilustra a limitaçáo do caráter social do programa, que tem sido mais identificado com políticas econômicas anticíclicas. Em particular, a maior concentração de unidades e valores contratados na capital fluminense e municípios da regiáo metropolitana de empreendimentos da faixa 1 no período inicial do programa, quando ocorreram as remoçóes para implementação das obras públicas de preparação da Cidade do Rio de Janeiro para receber megaeventos esportivos, particularmente as Olimpíadas de 2016.

O quarto artigo, de Gustavo Bezerra de Brito, José Borborema de Araújo e Glaucio José Marafon, "Espacialização do programa "Minha Casa, Minha Vida" no estado e na capital do Rio de Janeiro", buscou verificar por meio da análise dos dados quantitativos e cartográficos do ERJ e da capital, Rio de Janeiro, um possível aumento da segregação socioespacial no estado em função da renda, além da concentração de unidades habitacionais nas faixas intermediárias com maior poder aquisitivo - notadamente as faixas 2 e 3 . O quinto artigo, assinado por Lívia Miranda, Demóstenes Moraes e Juliana Peixoto de Araújo, "A inserção urbana de empreendimentos do Programa Minha Casa, Minha Vida em João Pessoa, Campina Grande e Patos, na Paraíba”, buscou desenvolver análises sobre a inserção urbana e a qualidade arquitetônica e urbanística dos empreendimentos produzidos pelo PMCMV em alguns municípios paraibanos: João Pessoa, Campina Grande e Patos.

No sexto artigo, de Eliane Campos dos Santos e Paula Dieb Martins, "Periferização da produção imobiliária no século XXI: a produção do Programa Minha Casa Minha Vida em João Pessoa - PB”, é feita uma análise acerca da estruturação do espaço intraurbano de João Pessoa para fundamentar a análise mais específica da produção habitacional vinculada ao PMCMV na 
cidade entre 2009 e 2018. O sétimo artigo, de Luciana Medeiros de Araújo, "PMCMV e produção imobiliária nas cidades de Patos e Cajazeiras /PB", apresenta resultados da pesquisa sobre a produção imobiliária e a expansão urbana das cidades de Patos e de Cajazeiras, ambas situadas na mesorregião do Sertão Paraibano, às margens da BR-230. Essas cidades compóem as Regiōes Intermediárias de Articulação Urbana, cujas áreas de influência territorial extrapolam os limites definidos por suas microrregióes geográficas e os limites estaduais.

O oitavo artigo, de Vania Regina Jorge da Silva e Miguel Angelo Ribeiro, "A produção imobiliária do PMCMV no bairro de Santa Cruz - Rio de Janeiro/RJ: Análises e contextos no período de 2005 e 2010", versa sobre a produção imobiliária do Programa Minha Casa Minha Vida (PMCMV) no bairro de Santa Cruz, localizado na Zona Oeste da urbe carioca e preocupa-se em observar as mudanças espaciais no referido bairro, relacionadas a uma gama de investimentos. O nono artigo, de Jéssica Liana de Souza e Doralice Sátyro Maia, “A produção do espaço urbano e o Programa Minha Casa Minha Vida em Russas - Ceará”, teve por objeto espacial a cidade de Russas, localizada no baixo Jaguaribe, Ceará, no Nordeste brasileiro. Este núcleo urbano possui 76.884 habitantes (IBGE, 2018), podendo, portanto, ser considerada uma pequena cidade. $\mathrm{Na}$ análise, buscou-se considerar a dinâmica socioespacial de um núcleo urbano no interior do território do Nordeste brasileiro com as suas particularidades e singularidades, sem ignorar o contexto global.

O décimo artigo, de autoria de Fábio Gustavo Pontes Martin e Marcelo Werner da Silva, "Uma crítica ao processo de autossegregação através da análise de três condomínios Minha Casa Minha Vida”, visou aprofundar o debate a respeito do processo de segregação urbana com uma visão crítica do conceito de autossegregação por meio da análise de três condomínios situados na cidade de Campos dos Goytacazes, produzidos no âmbito do maior programa habitacional do país, o Minha Casa Minha Vida (PMCMV), em sua modalidade empresarial. O décimo-primeiro - e último - artigo, de Sâmara Iris de Lima Santos, "A apropriação dos espaços de lazer no conjunto habitacional Major Veneziano (I, II, III, IV) em Campina grande, PB", efetua uma análise dos resultados da política habitacional do PMCMV em Campina Grande, optando-se por analisar o conjunto Major Veneziano, pois foi o primeiro conjunto entregue na cidade em 2011, destinado à faixa 1 do 
programa, ou seja, às famílias com renda até 3 salários mínimos conforme regia o documento do programa na época.

O livro representa o esforço coletivo de um grupo de pesquisadores associados a UNESP/PP, UFPB e UERJ, que através de missôes de trabalhos e reflexôes permitiu aprofundar a investigação sobre o Programa Minha Casa, Minha Vida.

Agradecemos a todos que contribuíram para materializar este trabalho e convidamos para uma leitura sobre esse importante programa de construção de habitação popular no Brasil.

\section{Referências}

CAMPOS, Paola Rogedo. "O preço da terra urbana e a moradia de baixo custo". In: MENDONÇA, Jupira Gomes de e COSTA, Heloisa Soares de Moura (orgs.). Estado $e$ Capital imobiliário: convergências atuais na produçâo do espaço urbano brasileiro. Belo Horizonte: C/Arte, 2011.

CARDOSO, Adauto Lúcio. (org.). O Programa Minha Casa Minha Vida e seus efeitos territoriais. Rio de Janeiro: Letra Capital, 2013.

LUCENA, Wilma Guedes de. "Habitação e Expansão Urbana: Análise do Programa Minha Casa Minha Vida nas Cidades de Campina Grande, PB e Caruaru, PE". Anais Encontro Nacional de Geógrafos. São Luís: Associação dos Geógrafos Brasileiros, 2017.

ROLNIK, Raquel e NAKANO, Kazuo. "As armadilhas do pacote habitacional". Le Monde Diplomatique Brasil. Ano 2, n. 20, março de 2009. Disponível em: http://www.diplomatique.org.br/artigo.php?id=461

SHIMBO, Lucia Zanin. Habitação Social de Mercado: A confluência entre Estado, empresas construtoras e capital financeiro. Belo Horizonte: C/Arte, 2012. 